\title{
Exploration and Practice of the Cultivation Mode of Innovative Talents in Applied Chemistry specialty
}

\author{
LI Yan \\ School of Nuclear Technology and Chemistry \& Biology \\ Hubei University of Science and Technology, Xianning \\ China,liyan750607@163.com
}

\author{
ZENG Zhi Gang \\ School of Nuclear Technology and Chemistry \& Biology \\ Hubei University of Science and Technology, Xianning \\ China, zzgang2012@ hotmail.com
}

\begin{abstract}
As a provincial university, applied chemistry specialty undergraduate education should take what kind of training mode, for economic construction and social development to provide university graduates of high-quality, innovative, adaptation ability is the problems that we have been thinking and exploring. According to the idea of innovative education, the cultivation mode of innovative talents is explored and practiced by cultivating students' innovative consciousness, strengthening the construction of teachers, improving teaching methods, strengthening the practice teaching links and improving the management mechanism. The practice has proved that the implementation of the above work has indeed improved the comprehensive quality and innovation ability of the students majoring in Applied Chemistry.
\end{abstract}

Keywords-applied chemistry; innovative talents; training mode introduction; explore; practice

At present, in the increasingly fierce international competition, the development of the country is more and more dependent on the high quality workers and a large number of innovative talents, more and more dependent on the level and quality of education. As a provincial university, applied chemistry specialty undergraduate education should take what kind of training mode, for economic construction and social development to provide university graduates of high-quality, innovative, adaptation ability is the problem that we have been thinking and exploring. To this end, we have carried out the exploration and practice of the training mode of innovative talents for Applied Chemistry Specialty in order to provide a reference for the chemical industry.

\section{ACTIVELY CUlTiVATING THE INNOVATIVE CONSCIOUSNESS OF THE STUDENTS}

Innovative consciousness is the premise of creation. Only the people who have made unremitting efforts to the unknown world and the truth will be in a positive and active attitude to study, practice and create. College teachers undertaking scientific research tasks have relatively stable research areas and they bring the latest achievements in the field of research, research status and some problems encountered into the undergraduate teaching, so that students can understand the application domain of the knowledge intuitively, stimulate the enthusiasm of students to participate in the scientific research projects of teacher, improve professional learning interest, and use the knowledge to try to solve some scientific problems, for future work and study to lay a good foundation. On the one hand, when students participate in the extracurricular activities of science and technology, they have a direct incentive to develop their own creative intention and motivation with, experience to the unprecedented sense of accomplishment, sense of mission and responsibility, so as to establish the spirit of scientific dedication. On the other hand, the development of extracurricular activities of science and technology will create a strong academic atmosphere, and promote and infect other students around the scientific research $[1]$.

\section{Strengthening the Construction OF TEACHING STAFF}

To realize the goal of the cultivation of innovative talents, the key lies in the teachers. Therefore, optimizing the teaching staff is the key to cultivate innovative talents. The construction of teaching staff includes the following two parts.

\section{A. Using the way of passing, helping, taking, and supervising to build a high level of teachers' team}

For the young teachers who just participated in work, they must worship an outstanding senior teacher with abundant teaching experience to attendant lectures, and to participate in counseling, answering questions, correcting exercises and so on. In this process, young teachers accumulated experience, strengthen confidence, accepted the examination at the same time. The examination qualified can be served as programs speaker. In the process, the senior teachers fully play the role of passing, helping, taking, and supervising. Before class, they listen to the lecture. Combined with specific theories and concepts, they discuss the teaching method with young teacher together. They give the young teachers encouragement and specific help. After the class, they exchange views with young teachers promptly, and ready to solve problems encountered in teaching at any time so as to ensure the quality of teaching. At the same time, the school also carried out young teachers classroom skills contest, excellent mentoring selection, pacesetter selection and other activities to attract young 
teachers to participate in educational reform, train young teachers and build a reasonable structure of the old, middleaged and young high level teachers echelon.

\section{B. Constructive teaching and scientific research, and constantly promoting the teachers to update their knowledge}

The duty of teachers in Colleges and universities is not only to carry out undergraduate teaching, but also to carry out scientific research and creative work; otherwise it will give rise to the situation of teaching stereotyped knowledge in the process of teaching. On emphasizing the teaching work is the bounden duty of the teachers at the same time, we also have to stress the importance to promote the scientific research work of the construction of teachers. Both domestic and international experience shows that it is impossible for a university to build a teaching staff of high quality without a high quality of scientific research. Nor it is possible to have a high level of education quality and scientific research without teaching staff of high quality. Through scientific research, teachers can understand the requirements of the society to the cultivation of talents, and understand the requirements of the society to cultivate the ability of entrepreneurship. The position of the whole subject and the logic in the course of the course, the new knowledge gained from scientific research and new technology to the teaching in time to[2].

\section{IMPROVING TEACHING METHOD}

\section{A. Using heuristic teaching}

As for the reform of teaching methods, carrying out the heuristic teaching is the key to our teaching reform. On the one hand, in the teaching efforts, try to change the idea of simply imparting knowledge and skills, strengthen the cultivation of the students' ability to analyze the question, to solve the problem and innovation ability training; in the teaching process, and gradually get rid of the teacher centered, classroom as the center of the cramming method of teaching, and vigorously promote the practice of heuristic and discussion teaching methods and the application of modern educational technology, increase the amount of information, improve teaching efficiency, fully mobilize and play the initiative and enthusiasm of students learning. On the other hand, we give full play to the teaching democracy and give the students a certain choice. Teachers do not easily deny the exploration of students, pay attention to the training of their development thinking. The teaching results are not satisfied and limited to teaching material, authority and the answer of the standard and so on, guide students to explore the process of knowledge formation rather than the memory itself. After each lesson can be left one or more interesting questions and organize class discussion at the appropriate time[5]. Such as asking some students to speak their own design of the experimental program on the stage in chemistry class, other students to complete it, the teacher slightly add comments, so that the students on the stage can get exercise, the students under the stage to be inspired. This will improve students' learning enthusiasm and active classroom atmosphere. In the whole teaching process, the teacher's role should be changed from "actor" to "director", and the role of students should be changed from "audience" to "actor".

\section{B. Using individualized teaching to teach students in accordance with their aptitude}

Admit students individual differences, respect for nature and specialty of students, teach students in accordance with their aptitude, implement personalized teaching, so that students can choose their own room and give full play to their potential in learning contents and requirements. To allow a portion of the outstanding students to come to the fore, so as to design more conducive plan for the development of these outstanding students, for example, you can make some outstanding students in the classroom finish their class learning task, at the same time let them go into the laboratory to participate in scientific research. In dealing with practical problems, they can gain the knowledge and cultivate creative thinking.

\section{Teaching students how to learn}

"Illiteracy in the future is not the people who don't recognize IV a single word any more, but did not learn how to learn". Therefore, teachers should not only teach the subject knowledge, but also teach the learning method, not only to let students "learn", but also to make the students learn to learn ". The formation of comprehensive ability is beneficial for converting education into self - education, we cannot put four years of valuable time of students in the university for only the inculcation theory knowledge, but cultivate students' sustainable learning ability to settle a good foundation for their self-education, self -development and self -perfection in the future, which is commonly referred to as "not only to teach him to fish, but also to teach him how to fish"[5].

\section{Strengthening Practical Teaching Link}

The practice teaching is the carrier of cultivating students' innovative thinking and comprehensive ability. According to the different stages of the students' ability formed and the law of the development, the practice teaching of applied chemistry profession can improve students' innovative spirit and project practice ability by chemical experiments, chemical engineering design and practice. To do this we have carried out the following exploration and reform:

\section{A. Strengthening the construction of laboratory, integrating the experimental links, improving the level of experimental teaching and cultivating students ' comprehensive ability of the students}

With the increase of the input in the experiment of the colleges and universities, the experiment course has been integrated and optimized. In the experiment, we can arrange some comprehensive and design experiment, which makes the teachers and students have some flexibility in teaching. In the comprehensive chemistry experiment, it is required to 
adopt the research teaching mode, and its content should be related to some scientific research projects, which can improve the advancement, leading edge and comprehensiveness of experiments. The design experiment and the innovation experiment of undergraduate students are combined, often only give the experimental purposes, encourage students to design the experimental method and the content and to complete the experiment by themselves, give full play to the students' creative thinking and practical ability by integrating the knowledge they learned and looking up literature. This will not only improve the students' ability to do the work, but also make the knowledge become a living knowledge, and ultimately converted into innovation ability[4].

\section{B. Carrying out industry university research cooperation and strengthening the practice base construction}

Chemical professional students in the school during the school period generally have three internship, understanding practice, production (Professional) practice, graduation (Design) internship. Schools should increase the investment in practice, as far as possible to allow students to go to some of the large-scale petrochemical enterprises with advanced management, technology, equipment and control to practice. Build a platform for students to understand the production and management of modern enterprise. For chemical engineering students, field training exercise is an indispensable link for students to exercise their ability of building mutual connection of book knowledge and engineering practice, of enhancing the perceptual knowledge, of developing practical ability and master the book knowledge well. "Cooperative education of industry and teaching" mode is an important way to establish a solid base of practice. Therefore, the choice and construction of the practice base is a very important part for training innovative talent. In recent years, the professional students in our school who went to the Yangtze Petrochemical, Jinling Petrochemical and other well-known large enterprises to practice received a very good effect[5].

\section{Optimizing curriculum design plan}

On the one hand, in addition to the students to do the graduation design, my school of Applied Chemistry Specialty Chemical Principle Course in general independent set of curriculum design link, small design. It can achieve comprehensive utilization and flexible use of the knowledge, which not only makes the students knowledge of the course as a system to achieve mastery through a comprehensive study of the subject's understanding and application, also make the students accept the preliminary engineering practical ability of basic training. So for students in the graduation design process design will increase its design capacity, and for the graduation design link to choose the students will not cause the lack of link capacity design, training[6]. On the other hand, we have to increase the weight of the graduation design, a part of the young teachers in the design of the formal training, in order to make the students' graduation design can be more standardized ${ }^{[7]}$.

\section{Perfecting Management System}

Reform teaching environment and management mechanism, establishing the academic environment that is helpful for the development of innovation talents, implement flexible credit system, tutorial system and free elective system, and gradually realize the academic environment of campus innovation. To this end, the school offers a broad space for college students' scientific and technological innovation activities, gives the hardware and software facilities and financial support, have built a number of open laboratories in succession. At the same time, in order to encourage and support students to participate in scientific and technological innovation and independent business activities, the school specially established the Hubei science and Technology College Students Extracurricular innovation and entrepreneurship fund. The school provides 300000 yuan of special funds for the fund annually. Students can declare some of their own good, innovative topics. By getting access to information, contacting the instructor and laboratory, filling in the application form and going through other procedures, the students can participate in research group to do the experiment after the assessment of the project. The subject is generally finished in 1-2 years[8]. During the process, there are many links include interim assessment and the acceptance of the subject and so on. For students who can make the results, the school will give them credit or material reward and use other ways to encourage them to do so. This can cultivate students' interest in scientific research and innovation awareness, so that students are subject to the initial research training. After several years of implementation, the system has achieved initial results; more and more undergraduates enter the laboratory in the second or third school year, the $y$ use spare time to participate in scientific research and innovation activities. Some of the students make innovative achievements in the undergraduate stage, which lay a good foundation for the learning stage of the graduate students. In practice, we believe that the necessary conditions for college students' scientific and technological innovation should be ensured, such as offering material environment, experimental conditions, providing the necessary space, funds and guidance, establishing sound stimulus mechanism and providing correct assessment and guidance. Meanwhile, we should stress that scientific innovation activities shouldn't affect the learning of theoretical course so as to ensure the healthy develop of College Students' scientific and technological innovation[9].

\section{CONCLUSION}

In short, the cultivation of innovative talents is the inevitable choice for applied Chemistry Specialty in twentyfirst Century. To cultivate people with creative ability is the duty of the whole society. In order to cultivate and bring up high quality and creative talents for the times, colleges and universities must conform to the trend of the times to actively, seriously, and fully strengthen the cultivation of students' innovative spirit and creative ability. This will produce more innovative students in school and create more 
innovative talents to make contribution to the modernization of the motherland and the construction of a harmonious society.

\section{ACKNOWLEDGMENT}

This Project was supported by Teaching Research Projects (focus) of Hubei University of Technology and Science (NO.2014-XA-010).

\section{REFERENCES}

[1] Guo Jia, Fan Qingchun, Luo Hua, et al. Exploration of new chemical research personnel training plane [J]. Guangdong chemical, 2007, 34(5):114- 118.

[2] Nanyan. Boron training mode of chemical engineering innovative talents of the 21st century[J]. China Adult Education, 2009, (15): 143 $-144$.

[3] Wang Jian college chemistry innovation talent cultivation mode exploration [J]. Xiangtan Normal College Journal: Social Science Edition, 2004, 26 (4):154-157.

[4] Fu Hong, Zhang Fengbao, Song Shumei, et al. The cultivation of innovative talents in chemical engineering and the practice of [J]. chemical engineering higher education, 2004, 1:6 - 7

[5] Du Weigang, Zhou Wei. College of chemical engineering and technology professional and innovative talents training model of gripper[J]. Journal of Xuzhou Institute of technology, 2006, 21 (1) 21:106 - 108 .

[6] Ping Xiang wang, Tie Jun tang, Liu Wei, Shen Pei. Construction of personnel training model innovation experimental zone exploration [J]. China University teaching. 2010, (05):50-52.

[7] Wang Jingfei, Gao Xiuhong. of institutions of higher learning in teaching reform of chemical experiment $[\mathrm{J}]$. science and Technology Innovation Herald, 2010 (15): 170.

[8] Sun Hong. The practice of higher normal science journal, green chemistry education in the teaching of organic chemistry experiment in 2008, 28 (3): 120

[9] Anastas P T,Warner J C . Green Chemistry:Theory and Practice[M]. NewYork:Oxford University Press,1998:29-55. 